\title{
Passagens, cenas, cartografias: pesquisando a produção do dispositivo "apoio" no município de São Bernardo do Campo
}

\section{| ${ }^{1}$ Ana Cristina Sundfeld I}

Resumo: A cartografia pode ser compreendida como uma estratégia que inspira a produção de pesquisas interessadas em traçar, acompanhar, investigar processualidades e propor movimentos de análise. Esse arranjo se mostrou potente para pôr o pensamento em movimento e suscitar sensibilidades que recortaram travessias e experimentaçóes durante a pesquisa de doutorado sobre a fabricação do apoio em saúde no município de São Bernardo do Campo, onde o apoio foi proposto como dispositivo agenciador de redes. As ofertas de apoio variavam em função dos encontros e seus agenciamentos, na perspectiva de que a produção do cuidado e da gestão mobiliza táticas conectadas e indissociáveis. O artigo apresenta momentos e recortes dessa experiência em cartografia, por meio de pequenas narrativas que ilustram inquietaçôes, acasos e imprevisíveis imanentes a esta geografia móvel e sua multiplicidade de possíveis. Nas andanças da pesquisa, foi possível acompanhar muitas maneiras de interrogar e produzir práticas cuidadoras entre os diferentes atores, que colocavam em circulação tensionamentos, disputas e a intensa conexão entre gestão e cotidiano do cuidado.

> Palavras-chave: cartografia; apoio; micropolítica do trabalho; produção do cuidado.

\author{
1 Doutorado, Faculdade de \\ Saúde Pública, Universidade de \\ São Paulo. São Paulo-SP, Brasil \\ (anacristinasundfeld@gmail.com) \\ ORCID: 0000-0001-5329-7555
}

Recebido em: 16/04/2019

Aprovado em: 13/01/2020 Revisado em: 30/06/2020 


\section{Cartografia como estratégia de pesquisa}

A produção do conhecimento é fortemente marcada pela criação de conceitos empenhados em definir, estabelecer, esclarecer, explicar, o que uma coisa é. Ao contrário da imagem do pensamento e de sua vocação para a produçáo do conceitorepresentaçáo e de relaçóes causais e explicativas, propomos o pensamento como operação suscitada por algo que afeta, que provoca um embate de forças e cria uma perspectiva - ou seja, sentido, valor, consistência, realidade. No lugar da representação de algo, interessam-nos o movimento, a produção de paisagens e seus deslocamentos, os processos de subjetivação a que dão passagem. Um tipo de pesquisa cuja pergunta se orienta para os processos nos quais afetos, ideias, subjetivaçôes e desejos produzem sujeitos e mundos, perspectivas e multiplicidades.

A cartografia recusa a ideia de desvelamento do objeto como se sua existência fosse a priori para afirmar sua produção a partir do encontro com aquilo que compóe e atravessa: afetos, ideias, açôes, subjetivaçóes, desejos. É somente na imanência que o campo é experimentado e é possível saber com o outro, ao invés de falar pelo outro ou sobre o outro. O conhecimento, no domínio desse tipo de pesquisa, é fatalmente marcado por uma importante provisoriedade de métodos e conceitos capazes de fluir na imanência com aquilo que se move, com aquilo que precisam exprimir em movimento.

$\mathrm{Na}$ perspectiva cartográfica, sujeito-objeto se implicam, tensionam juntos, se afetam, numa provocação às formas cristalizadas do pensamento, permanente convite à invençấo de si e do mundo: "sujeito e objeto se fazem juntos, emergem de um plano afetivo”(BARROS; KASTRUP, 2009, p. 73). Diferente do mapa, cujas rotas estão traçadas em direção a um destino previamente estabelecido, a experiência cartográfica propõe um conhecer fazendo, acompanhado de surpresas, do inusitado, da criação que exige colocar em risco certezas, pressuposiçôes, conceitos. Dependendo dos encontros e das afecçôes, certas visibilidades são produzidas; outras, não.

A cartografia se constitui como abordagem que se conjuga com os verbos percorrer, acompanhar, mergulhar, afetar, misturar. Trata-se de um mergulho intensivo no cotidiano, nos processos de produção do real, mobilizado por curiosidade, interrogaçôes, desejos e inquietaçôes. As perguntas-guias se movem, se misturam e se transformam durante o trajeto no qual cartógrafo-campo se compóe 
em constante processualidade. Parte-se com uma mochila de preocupaçôes e apostas num itinerário aberto e mutante.

Caminhar em involução, nem de onde, nem para onde, mas habitar as múltiplas temporalidades num único instante. E perguntar, que é que insiste aqui? Que é que pede passagem na língua? Que é que ganha verbo no que acontece? (COSTA; ANGELI; FONSECA, 2012, p. 46).

\section{O dispositivo "apoio": sentidos e potências}

O apoio é marcado pelos agenciamentos de múltiplos referenciais teóricos, práticas de gestáo e interesses que organizam os processos de trabalho e a produção do cuidado. Essas conexôes fabricam diferentes arranjos que assinalam a heterogeneidade do apoio.

As primeiras formulaçóes sobre o apoio (CAMPOS, 2007) destacam sua especificidade em relação à ideia de supervisão, tal como aparece nas teorias de administração, em especial no taylorismo. Essa distinção relaciona o apoio ao compartilhamento, à (auto)análise crítica e à formulação de práticas sempre no/e com o coletivo, ao passo que a supervisão numa perspectiva clássica opera sobre o coletivo por meio de fiscalização, avaliação e ajustes em direção a normas e metas previamente estabelecidas.

A supervisão comporta vários desenhos de acordo com o arranjo organizacional e a concepção administrativo-gerencial que a sustentam. Apesar de ser intitulada "supervisão", na saúde mental esse dispositivo foi instituído para apoiar o processo de reforma psiquiátrica, contribuindo para novos modos de pensar e cuidar em saúde mental. Nesse campo, em diálogo tanto com a produção da análise institucional, como com a psicanálise, há o reconhecimento da necessidade da análise da implicação ou da transferência - dependendo da referência - e aí o apoio vem engravidado de outras possibilidades.

Autores que ao longo dos anos 80 e início dos anos 90 se reuniam em torno do Laboratório de Planejamento e Política em Saúde, na Unicamp, numa perspectiva chamada de "defesa da vida", ocuparam-se de construir dispositivos e conceitos que possibilitassem romper com a fragmentação do cuidado e a burocratização das relações de trabalho impostas pelo controle sistemático do trabalho vivo na saúde.

Inspirando-se na experiência acumulada no campo da saúde mental/luta antimanicomial, trouxeram para a Saúde Coletiva conceitos como acolhimento, 
vínculo, referência, ferramentas para colocar em análise o processo de trabalho em saúde, arranjos do processo de trabalho, como as unidades de produção, que possibilitassem trabalho compartilhado e criatividade. Nesse movimento vem também a ideia do apoio, fortalecida pelo diálogo desses autores com a análise institucional, como uma estratégia de aproximar a gestão do cotidiano do trabalho e de favorecer a autoanálise das equipes em relação aos arranjos e processos de trabalho.

No início dos anos 2000, Campos propôs o método Paideia, que articula vários elementos dessas experiências anteriores, só que organizadas em um método com dispositivos definidos. Em suas palavras, seus objetivos são o fortalecimento dos sujeitos e a construção da democracia institucional por meio da criação de espaços coletivos compreendidos como "arranjos concretos de tempo e lugar, em que o poder esteja em jogo; e onde, de fato, se analisem problemas e se tomem deliberaçóes” (CAMPOS, 2007, p. 42).A figura do apoiador institucional agencia a construção desses espaços coletivos, estimulando o diálogo e a análise das necessidades e conflitos cotidianos. As equipes de referência e o apoio matricial são definidos como arranjos organizacionais com potencial para ampliar o poder das equipes em relação aos processos de trabalho por meio de negociaçôes, troca de saberes e decisóes conjuntas (CAMPOS; DOMITTI, 2007).

Campos faz uma distinção entre apoio institucional e apoio matricial. O apoio institucional está relacionado à ampliação da capacidade de análise e de participação dos trabalhadores na gestão por meio do diálogo e da corresponsabilização; o apoio matricial se refere às ofertas de conhecimentos dos variados núcleos profissionais e suas articulaçóes para a composição do cuidado integral e centrado nas necessidades do usuário.

No começo dos anos 2000, as proposiçóes sobre o apoio foram organizadas no âmbito da Política Nacional de Humanização (PNH), que adotou e difundiu o método Paideia compreendido como um método de inclusão, disparador da criação coletiva de cuidado e estratégias de gestão numa perspectiva democrática, que decorre do acolher e incluir as diferenças com os tensionamentos implicados em tal processo:

A inclusão produz, portanto, a emergência de movimentos ambíguos e contraditórios, os quais devem ser sustentados por práticas de gestão que suportem o convívio da diferença e a partir dela sejam capazes de produzir o comum, que pode ser traduzido como projeto coletivo (PASCHE; PASSOS, 2010, p. 426). 
Nesse cenário, a função do apoio é absorvida como exercício do método da PNH: "um modo de incluir novos parceiros, multiplicando os agentes de contágio da política pública de saúde" (PASCHE; PASSOS, 2010, p. 429). O apoiador tem a função de provocar questionamentos, reflexôes, inclusão das diferenças e construção de posicionamentos com o coletivo.

O apoio vai se configurando, portanto, como um recurso para a produção de mudanças nos planos da gestão e do modelo de atenção por meio da ampliação da democracia institucional. $O$ apoiador se constitui como referência para o coletivo ao longo do tempo e de certa estabilidade de encontros que possibilitam a construção de relações de confiança e o compartilhamento de dificuldades, dúvidas e tensionamentos; apoiador e coletivo estabelecem contratos de trabalho com espaço para a análise e discussão do processo de grupalização, no qual o apoiador se inclui na condição de um "não-lugar", provisório e fronteiriço.

Voltar ao mesmo coletivo, suportar a crítica ou a explicitaçáo de situação que inviabilizou
a realização do que foi acordado, reposicionar-se, insistir, mudar a velocidade ou aban-
donar caminhos (mesmo aqueles que nos custam tanto a abandonar, que pareciam táo
promissores...), recontratar, avaliar junto ao coletivo, comemorar avanços, compreender
e superar as derrotas, buscar mais e novos suportes conceituais, dialogar com eles, jogar
alguns fora, procurar novas explicaçóes (porque as que tínhamos já não dão conta do que
a vida foi demandando)... tudo isto faz parte do cotidiano do apoio e compóe a dinâmica
de trabalho do apoiador (PAULON; PASCHE; RIGHI, 2014, p. 813).

Baduy (2010) e Bertussi (2010) destacam que a caixa de ferramentas do apoiador é construída em ato e pode contribuir para ampliar porosidades, mobilizar desterritorialização e produção de novos territórios cuidadores. Ademais, todo gestor pode ter dentro de suas funçóes o papel de apoiador e todos os trabalhadores da saúde têm a função apoiadora com uma possibilidade entre suas ofertas, tanto no âmbito da relação com os demais trabalhadores, como em relação ao apoio que pode ser desenvolvido com o usuário no ato da produção do cuidado.

Apoio é algo que se produz no encontro, partindo das tensōes e questôes do cotidiano - da gestão e da atenção -, é produzido a partir de múltiplas relaçóes que afetam e mobilizam e que devem ser analisadas pelo próprio grupo. Muitas vezes causam desconforto. Esse desconforto e a possibilidade de reflexão crítica são fundamentais para a produção de novos arranjos e saberes (BRASIL, 2014).

No percurso do doutorado, fui me aproximando das experiências do apoio por meio de alguns apoiadores do município de São Bernardo do Campo (SBC), que 
faziam parte do grupo de pesquisa e compartilhavam suas experiências cotidianas, aguçando minha curiosidade e interesse. $\mathrm{O}$ arranjo singular do apoio e suas práticas no município dispararam desejo de percorrer suas linhas de criação. As conversas potencializaram inquietaçóes, até que se desenhou um campo problemático: o apoio como dispositivo e sua potência para disparar movimentos, análises e transformaçóes na produção do cuidado. ${ }^{1}$

A investigação sobre o apoio em saúde pareceu uma aposta interessante, uma possibilidade de experimentação cartográfica. A pesquisa foi se desenhando em diálogo com as perguntas-guias e suas composições: como o apoio é fabricado? Como opera no cotidiano? Que efeitos produz? Poderia tal dispositivo atuar como intercessor, contribuindo no combate de práticas prescritivas e provocando devires criativos para o cuidado?

A construção do conhecimento é inseparável de uma aposta ético-política que implica o pesquisador desde suas interrogações iniciais. Aopção pelas experimentaçôes cartográficas está ligada a afirmação de um conhecimento implicado, crítico, processual, interrogativo, que convida a reflexôes éticas e desconstrução da imagem tradicional do pensamento.

\section{Apostas para o apoio no município de SBC}

A formulação do apoio em SBC foi atravessada pela heterogeneidade das produçóes sobre o tema e trouxe uma forte aposta no apoio como agenciador de conexóes.

O processo de territorialização da saúde no município originou nove territórios; cada um contava com uma equipe de apoiadores, constituída por trabalhadores com formaçôes variadas como Fisioterapia, Fonoaudiologia, Psicologia, Educação Física, Terapia Ocupacional, Nutrição, Sociologia, Enfermagem, etc. As equipes tinham arranjos singulares, heterogêneos e mutáveis: em alguns casos, se distribuíam como referência para os serviços, com presença mais cotidiana nas UBS e na UPA; em outros, se organizavam como referência por projetos (mortalidade infantil, saúde mental, violência, etc.), circulando na rede e fazendo transversalidade no território. Eram vários jeitos de organizar a entrada do apoio e suas articulações com os serviços, movimentados pelas agendas disparadas pela gestão, pelos afetos, pelos vínculos e parcerias construídos.

Cada equipe de apoiadores contava com uma dupla de facilitadores de educação permanente ligados à gestão nos diferentes departamentos da Secretaria de Saúde 
que dava suporte à análise dos processos de trabalho como organização das agendas, discussão de casos complexos e articulação com outros serviços. Ademais, contava com orientadores de educação permanente com a função de facilitar os processos de educação permanente nos territórios.

Mensalmente acontecia uma reunião de educação permanente denominada EP do apoio com a presença de todos os apoiadores, facilitadores do apoio e referências do território (membros da equipe de gestão da atençâo básica designados para acompanhar determinados territórios) com o objetivo de produzir análise das práticas cotidianas, planejamento e pactuação de açôes apoiadoras nos territórios.

Essa aposta na educação permanente (EP) como dispositivo de gestão ia além dos encontros cotidianos do apoio com as equipes nos serviços e das reunióes de EP do apoio. A EP de território foi proposta como um dispositivo para favorecer a produção de rede, o qual reunia gestores, profissionais de diferentes serviços do território como UBS, UPA, CAPS, hospitais e outros, apoiadores, orientadores, facilitadores do apoio e referências do território. Tratava-se de uma aposta com potência para produção de análise sobre as práticas de cuidado, arranjos, feitos, efeitos, novas apostas e também "lugar de identificar referências, fazer redes". ${ }^{2}$

Os nove territórios foram concebidos como espaço vivo, mutante, que abriga num mesmo campo multiplicidades e contrastes relativos à geografia, urbanização, vulnerabilidade social, cultura, etc. A ideia que estimulou a criação da EP de território foi produzir visibilidade para as disputas que operam na construçáo dos projetos de saúde no cotidiano, provocar reflexôes e problematizaçóes sobre os modos de cuidado, além da construçáo de acordos e pactos com base em novos sentidos produzidos para o trabalho e para os problemas.

Outro espaço disparador de conexôes era denominado Kanban, reunião que acontecia no Pronto-Socorro Central e no Hospital de Clínicas para discussão de casos envolvendo trabalhadores do hospital e apoiadores. O propósito desses encontros era pensar a gestão do cuidado dentro do hospital, a administração de recursos e leitos e a articulação de rede para a continuidade do cuidado. Nessas reunióes eram abordados procedimentos, situação do paciente e seguimento do cuidado. Amplamente reconhecido na rede de SBC, constituiu-se como uma composição potente para gerar projetos de cuidado no território por intermédio dos apoiadores.

O projeto de pesquisa foi aprovado pelo Comitê de Ética em Pesquisa (CEP) da Faculdade de Saúde Pública da Universidade de São Paulo em abril de 2014, sob 
o $\mathrm{n}^{0}$ CAAE 16633913.9.0000.5421. O estudo atendeu às diretrizes propostas na Resolução no 466/12 (BRASIL, 2012).

Durante um ano e dois meses, acompanhei o dia a dia dos apoiadores, deslocamentos e movimentos de conexão entre unidades de saúde, Centro de Atenção Psicossocial, pronto-socorro, hospitais, escola, conselho tutelar, etc. A pesquisa se fez percorrendo territórios e construindo interlocução com os atores no intuito de compartilhar os processos de trabalho cotidianos, movimentos, desterritorializaçóes, reterritorializações e seus efeitos.

Os deslocamentos possibilitaram conhecer diversos territórios, com características peculiares e contrastes expressivos. Acompanhei apoiadores de três territórios; dois deles (A e B) eram áreas urbanas, cujos serviços de saúde de referência como UBS, UPA, Centro de Especialidades e CAPS se concentram nos limites de sua abrangência e vizinhança próxima; o terceiro (C) constitui região de manancial, com áreas diferenciadas e acesso por meio de balsa, cobertura de UBS e UPA, e demais serviços de saúde referenciados na região central do município. Geografias que também agenciavam diferentes necessidades, vulnerabilidades, processos saúdedoença e criação de estratégias.

A pesquisa se compôs por meio de fontes variadas. Cada sujeito da pesquisa foi tomado como autor, expressão viva e produtora de sentidos que, na relação, movimentou regimes de visibilidade e de dizibilidade, como mosaicos distintos e singulares. Documentos, diário de campo, narrativas, conversas, textos, afecçóes, o diálogo com estas diversas fontes suscitaram problematizaçôes, questionamentos e composiçôes acompanhados de uma atitude de crítica e de suspeita, de recusa a qualquer totalização ou ideia de verdade:

Todas as entradas sáo boas, desde que as saídas sejam múltiplas. Por isso o cartógrafo serve-se de fontes as mais variadas, incluindo fontes não só escritas e nem só teóricas. Seus operadores conceituais podem surgir tanto de um filme quanto de uma conversa ou de um tratado de filosofia. O cartógrafo é um verdadeiro antropófago: vive de expropiar, se apropriar, devorar e desovar, transvalorado (ROLNIK, 2006, p. 65).

O cartógrafo experimenta devires no decurso da pesquisa; por isso é importante que ele sustente uma atitude de análise acerca de sua implicação no campo, permanente atenção e indagação sobre os afetos, inquietações e movimentos que nele operam:

$\mathrm{O}$ pesquisador in-mundo emaranha-se mistura-se, afeta-se com o processo de pesquisa, diluindo o próprio objeto, uma vez que se deixa contaminar com esse processo, e se sujando de mundo, é atravessado e inundado pelos encontros (ABRAHÁO et al., 2013). 
A ferramenta "diário de campo" foi fundamental no processo de pesquisa. Registro de ideias, desejos, cenas, cuja leitura provocava desdobramentos, surpresas, olhares distintos. Diferentes encontros, vínculos e afetos. Aprendizado que se fez nas relações, num tempo estabelecido pela sensibilidade e pelas afetaçóes que imprimiram ritmos próprios ao escutar, perceber, sentir, falar, esperar, calar. A análise permanente dessas afetaçôes ia armando outros modos de estar com os apoiadores, outras texturas de sensibilidade e de escuta, outras produções de subjetividade nos encontros.

\section{Itinerários cartográficos: a pesquisa em ato}

Os itinerários foram desenhando espaços de convivência e de conexão: sujeitos-experiência-sensibilidade-pensamento, num mútuo afetar-se. No decorrer da pesquisa, desdobraram-se processos de subjetivação, diferenciaçôes que se produziram movidas pela multiplicidade de afetaçôes:

Afetar denuncia que algo está acontecendo e que nosso saber é mínimo nesse acontecer. Sinaliza a força de expansão da vida e da atividade que podemos viver. A tensão se instala. O que se passa? (LAZZAROTTO; CARVALHO, 2012, p. 26).

Os encontros fabricaram agenciamentos diversos: alegrias, cumplicidades, silêncios, queixas, angústias. Em muitos momentos questionava minha postura, não estava ali como observadora desinteressada, portanto: deveria participar mais ativamente das discussōes? Compartilhar minhas impressōes? Problematizar questōes delicadas? Em que circunstâncias? Estas e outras tantas questóes perpassaram todo o processo, se colocaram às vezes em ato, no momento mesmo do encontro, às vezes no processamento dos afetos.

Esta pesquisa tem muitos começos: um deles é uma manhã de sexta-feira, quando me reuni com as apoiadoras e com a facilitadora/referência da atenção básica (AB) para apresentar o projeto. Cheguei ao local pelo menos meia hora antes do horário previsto. Aguardei sentada na sala de espera, ansiosa para conhecer as pessoas, falar, escutar, combinar as primeiras atividades, experimentar o dia a dia do apoio. Quando todas chegaram, nos acomodamos ao redor de uma mesa, numa sala espaçosa. Apresentei a proposta da pesquisa, falei das curiosidades que me instigavam a estudar a fabricação do apoio e a estratégia da cartografia. Entre uma frase e outra, o grupo fez perguntas, comentários e questionamentos: "Por que a escolha desta equipe? Deste território? É interessante conhecer outros também porque as 
realidades são muito diferentes umas das outras. Este território não define o que é o apoio em SBC", disse uma apoiadora com ar de surpresa. "Uma pesquisadora nos acompanhou por alguns meses e não deu nenhum retorno. Não sabemos o que ela escreveu sobre a gente", acrescentou outra apoiadora. A facilitadora/referência da AB fez o seguinte comentário: "Incomoda ver o trabalho exposto e sujeito a críticas, dá uma sensação de persecutoriedade, mas ao mesmo tempo pode ajudar trazendo uma visão de fora que pode auxiliar com ajustes e melhorias".

"Nossa equipe é uma das poucas que está junta desde o início, com a mesma composição", falou uma apoiadora. Ao ouvir esse comentário, pensei: "Legal, elas viveram diferentes momentos do processo de apoio juntas, tem muitas histórias e vivências para contar!". Uma das apoiadoras me olhou nos olhos e disse: "É para trabalhar junto e não sugar". Nesse momento as pessoas se olharam meio sem graça e a sensação de calor subiu: pude sentir minha roupa colando de suor, o rosto quente, os cabelos molhados! As falas expressavam incômodos, suspeitas e desconfiança. Eu quase podia ouvir seus pensamentos, enquanto me olhavam atentas: "Será mais uma pesquisadora que veio nos observar e aplicar questionários, sem compartilhar suas impressões, guardando mistérios sobre seus escritos e análises?”.

Durante a conversa, fui invadida pela sensação de desconforto e pela preocupação com a construção das relaçôes, não queria que me grudassem à imagem da doutoranda invasiva. Durante a reunião, tomamos café, reclamamos do calor e me vinham sensaçôes, palavras e pensamentos: "Aquela pesquisadora sabida que vinha fiscalizar, averiguar, avaliar, se meter; meu interesse era me misturar, estar junto, aprender".

Seria possível diluir essas posturas defensivas e construir parceria com as apoiadoras? O discurso racional acadêmico somado a certa postura militante foi mostrando sua fragilidade. A vontade era encerrar aquela conversa e sair correndo. Sustentei a ansiedade, mal tínhamos começado a reuniáo. Combinamos que as andanças pelo território seriam pactuadas de acordo com a agenda, a disponibilidade e as sugestôes do grupo, assim o caminho seria traçado a cada semana e o tempo de permanência definido durante o processo. Ao final da conversa, uma apoiadora me disse: "Uma tarefa de casa, ler o Programa de Melhoria do Acesso e da Qualidade da Atenção Básica (PMAQ)". ${ }^{3}$

Parti levando angústias, receios e interrogaçóes. Começo (in)tenso, acompanhado de expectativas e incertezas, preocupação de ser aceita e reconhecida pelas apoiadoras pelo interesse em conhecer a produçáo do apoio, mergulhando no cotidiano delas. De 
volta para casa, no ônibus, indagaçôes atravessaram a fabricação da " "pesquisadora em mim”, medos, inseguranças e dúvidas: serei acolhida nos espaços? Construiremos vínculo de confiança? O que fazer com as dificuldades, os percalços e o não sei?

Fui conhecendo as equipes, os gerentes, me misturando nos espaços coletivos, conhecendo o território com as apoiadoras e as ACS, além da UPA e das UBS. As unidades estavam reformadas, com fachada e pintura novas, espaço de recepçáo e salas de atendimento com acomodaçôes confortáveis. Escutei este comentário de uma ACS: "Após a reforma, aumentou a procura, as pessoas gostam de vir para a unidade depois que ela ficou bonita".

Com as andanças, o diário de campo foi ganhando volume e consistência; outros olhares, ideias, perspectivas, afetaçóes, de onde pouco a pouco foram se desenhando mapas analíticos da experiência, do cotidiano, dos encontros. A análise foi feita debruçando-me sobre os planos de produção em jogo, os quais engendram numa coemergência pesquisador-mundo; a análise é sempre análise de implicação, na qual nos colocamos em questão, nos interrogamos.

Muitas cenas, tensionamentos, paradas, bloqueios, mergulhos, exercícios de análise. Momentos em que uma sensação de naufrágio aos poucos contagiava o corpo, enrijecendo a pele e reduzindo poros, aberturas, entradas. Momentos em que escritos-catárticos misturavam-se a relatos angustiados. Irritabilidade, impaciência, desânimo. Marcas do que "não dava certo" recobriam outros olhares, obscurecendo os bons e os maus encontros, as construçôes e desconstruçôes.

Passagens difíceis e dolorosas, embates entre o ideal e a produção viva, rachaduras que se abriam sobre expectativas, teorizaçóes, apostas e desejos, liberando pouco a pouco diálogos e análises em fluidez com as experiências, retomadas da memória intensiva com gosto, cheiro, som, imagens: o que se passou, como, o que é potência, o que é problemático, como estes aspectos se conjugam. Outros escritos, outras produçóes, outras visibilidades...

A reunião da EP de território aconteceu numa sexta-feira pela manhã. Estávamos em meados de dezembro e em algumas salas da unidade havia decoraçóes natalinas. As pessoas iam chegando e colocando sua contribuição numa mesa que aos poucos estava repleta de sucos, refrigerantes, pães, bolos e biscoitos. No grupo tínhamos a orientadora de EP, seis ACS, uma gerente da UPA, duas gerentes de UBS, a gerente do Centro de Referência em Saúde do Trabalhador (CEREST), um profissional de 
arte educação (facilitador de grupos nas UBS), a assistente social do território (B), uma referência da vigilância sanitária, uma facilitadora do apoio (departamento de urgência/emergência), quatro apoiadoras e uma técnica do sistema de informação.

Múltiplos planos compondo este encontro, relacionados aos vínculos, a abertura para compartilhar dificuldades e pedir ajuda, a fabricação de autoanálise e mobilização. Dentre as composições em ato, tínhamos as conexões que o orientador de educação permanente produzia, movidas pela sensibilidade para se misturar ao coletivo e disparar questôes, além do uso de ferramentas de análise capazes de provocar problematizações que possibilitaram reflexão sobre os processos, aprendizagens compartilhadas e efeitos das açóes cotidianas.

A gerente do CEREST fez uma apresentação sobre saúde do trabalhador, abordando as relaçôes entre trabalho e identidade, trabalho e saúde e os riscos decorrentes da organização do trabalho. Em seguida, a orientadora de EP comentou:

O grupo vinha conversando sobre a relação entre sofrimento e processos de trabalho. Falamos sobre três momentos: antes do adoecimento, durante (com afastamento em alguns casos) e o retorno. Discutimos sobre a acolhida da equipe, a escuta do gerente e também a especificidade do trabalho em saúde. Temos muitos casos de depressão.

Repentinamente uma ACS indagou: "Quem vai ouvir o trabalhador?”. "As reuniôes de EP e as reunióes de equipe podem ser espaços de apoio para o trabalhador", respondeu a orientadora. Outra ACS perguntou baixinho: "E há espaço para isso?”. "Às vezes lavamos roupa suja entre nós, sem o médico e o apoio", comentou uma ACS. "Nem sempre tenho quem me escuta quando necessito!", lamentou outra ACS.

As falas acima provocaram comentários entre o grupo. A orientadora aguardou os ruídos cessarem e disse:

Há momentos de solidão no trabalho. Temos espaços para cuidar dessa solidão? Vamos pensar juntos. Vocês podem se organizar em pequenos grupos e responder: quais as situaçôes ou espaços que geram sofrimento, quais espaços que existem ou que podem ser criados para produzir saúde. Cada grupo escolhe um relator.

As pessoas se organizaram em três grupos. No grupo em que eu me reuni estavam uma apoiadora, duas ACS e uma técnica do sistema de informação. "E então quais os espaços que vocês acham que gera sofrimento?”, indagou a apoiadora. Logo uma ACS respondeu: "Ah, quando tem falhas operacionais na recepção é horrível! Fica uma confusão e todo mundo fica atrapalhado!". "E o povo não quer nem saber!”, completou outra ACS. "Sim, às vezes acontece. O sistema falha mesmo! A gente se 
empenha pra não acontecer, comentou a técnica do sistema de informação". "E o que mais?", provocou a apoiadora.

A porta se abriu e uma pessoa chamou uma das ACS: "Volto já", ela disse para o grupo. "Eu acho que o que pega mesmo é quando a gestão fala algo que ela mesma não acredita!", disse a técnica do sistema de informação. "A incoerência entre o dito e o feito?”, perguntou a apoiadora. A técnica balançou a cabeça num gesto afirmativo e continuou: "Também! E o pior é que você vê que aquela pessoa está dizendo algo só por dizer por que no fundo ela mesma sabe que é mentira!".

De volta, a ACS apressadamente disse: "E as reuniōes de equipe?”. "O que você acha?”, questionou a apoiadora. "Ah, às vezes tem o espaço físico e mais nada. As pessoas não se ajudam", lamentou a ACS. "Eu acho que as reunióes podem ser de fortalecimento do coletivo", opinou a técnica do sistema de informação. Olhando para sua colega, uma das ACS disse: "A gente nem tem reunião de ACS!". "Mas isso pode acontecer em qualquer reunião, reunião de equipe, reunião geral”, pontuou a técnica. "Nós podemos pensar em fazer uma reunião nossa", comentou uma das ACS. "Outro aspecto importante é a gente pensar nos processos de trabalho e fazer mudanças”, disse a apoiadora.

Depois de um tempo, a orientadora pediu: "Gente, vamos voltar para a grande roda e o relator de cada grupo apresenta uma síntese da conversa”. Uma apoiadora, com a caderneta na mão, apontou para as componentes do grupo e disse:

Esse é o grupo. Nós conversamos sobre as situaçóes ou espaços que geram sofrimento, como
as falhas no sistema operacional e as incoerências da gestão que às vezes diz uma coisa, mas
parece duvidar daquilo. Sobre os espaços que existem ou que podem ser criados para pro-
duzir saúde, achamos que são os espaços de reunião, reunião de equipe e geral. Pensar sobre
os processos de trabalho, o que precisa mudar, também ajuda a produzir saúde.

"O que eu quis dizer é que a gestão pede coisas e às vezes cobra coisas que ela mesmo sabe que não dá pra fazer, nem ela acredita naquilo!”, explicou a técnica do sistema de informação. Uma das gerentes de UBS ficou com uma expressão séria, franziu a testa e reagiu num tom hostil: "Não é tão simples assim! Nós também sofremos cobranças!”.

Nesse instante fui tomada por uma enxurrada de questionamentos e pensamentos: será que as "incoerências" são somente da gestão? Em que medida refletimos sobre o que fazemos e/ou apostamos no que dizemos? Os discursos e práticas são atravessados por interesses, poderes, reaçôes, silenciamentos e tantas outras coisas! 
Criticar o outro às vezes é uma esquiva para não se colocar em análise. Além disso, dependendo da situação, as pessoas se referem à gestão como algo de cima, do outro. $\mathrm{O}$ assunto provocou uma resposta defensiva e embaraço nas pessoas que ali representavam a "gestão"...

Outro relator rapidamente começou a falar. Leu o nome das pessoas do grupo e disse:

Nós identificamos vários espaços de adoecimento, mas também temos sugestôes. As pessoas se queixaram da rotina, da falta de escuta dos gestores, do excesso de demandas gestáo e administrativo, de sofrimento quanto à adaptaçấo ao PSF, falta de apoio e de sentido nas reunióes de equipe.

"Alguns médicos reclamam que vão ter que deixar de atender certos pacientes com o PSF", comentou baixinho uma ACS. A assistente social do território se queixou: "Às vezes me sinto exausta pra dar conta dos casos sociais". "Rotina tem em todo lugar", falou uma ACS. Observei movimentos na sala. Algumas pessoas falavam entre si; outras mexiam no celular. Uma das gerentes de UBS deu um suspiro e disse: "É estressante ser porta-voz".

A orientadora de EP sublinhou:

Todos somos gestores, lembram? Nós já discutimos isso. É necessário pensar no espaço de governabilidade que cada um tem e nos papéis também, às vezes nos colocamos em certos papéis, por quê?

A gerente permaneceu em silêncio. $\mathrm{O}$ relator do grupo continuou:

Bem, tem também as propostas: qualificar as reuniōes, grupos de arte e dinâmicas para os trabalhadores, encontros inter serviços para discutir casos, parcerias com instituiçôes próximas, espaço de escuta para o trabalhador com agenda fechada e grupos de apoio mútuo com mediação e autonomia.

"Criar novos grupos pode ser interessante, mas porque não aproveitar os espaços que já existem? Eles podem ser lugares de produção de saúde”, falou a facilitadora do apoio. "É importante pensar sobre o sentido desses espaços. A reuniāo de equipe, por exemplo, pra que serve?", provocou a orientadora de EP. Outro relator comentou:

Qualquer espaço pode levar ao adoecimento! Nosso grupo discutiu que jeitos diferentes de trabalhar, falta de incentivo profissional, baixa remuneração, alta demanda, excesso de jornada e falta de reconhecimento são coisas que adoecem. Mas há coisas simples que ajudam como o elogio no trabalho, também decisóes mais coletivas, ter espaço físico para descanso, abertura para diálogo e troca de experiências. 
As pessoas já se movimentavam nas cadeiras. Uma e outra levanta para pegar um café. A facilitadora do apoio fez o seguinte comentário: "Esse exercício em grupo foi bem bacana, vocês perceberam que a fabricação da saúde foi relacionada à qualidade das relações?”. "E a possibilidade de construção compartilhada de decisões também!", acrescentou a referência da vigilância sanitária. A orientadora de EP sorriu e encerrou o encontro num tom animado: "Eu acho que nossa manhã foi muito produtiva e esse é um exemplo de que os espaços coletivos podem ser potentes! Continuaremos a discussão depois do almoço”.

A potência da EP é ampliada pelo uso de ferramentas de análise que favorecem reflexōes sobre os desconfortos que afetam gestores, trabalhadores e apoiadores como os limites da autonomia para enfrentar problemas, propor e efetivar soluções, além de tensionamentos entre a democracia de processos e pressóes sobre falas em espaços coletivos. A proposta de transversalização da secretaria ampliou os encontros entre gestão central e territórios, mas eram constitutivas as disputas de projeto, os conflitos, ruídos, nós críticos e diversas reaçôes de enfrentamento, de silenciamento, de negaçáo, etc. A aposta na transversalização amplia as possibilidades de manejar essas disputas, nunca as elimina.

Vale destacar que somente a criação de espaços ou arranjos coletivos não é suficiente para definir sua operação. Os agenciamentos e as possibilidades de operação são múltiplos, e todos os espaços e arranjos precisam ser cuidados. Quer dizer, é preciso refletir sobre sua produção, incômodos, invençôes, disputas, eliminar barreiras, atuar favorecendo a potência. Nada está automaticamente dado. A produção de redes é imanente aos processos de trabalho em saúde, tem potência para desenhar mapas com variadas conexóes, trajetos, bifurcaçôes, saídas. Contudo, as redes podem cristalizar conexôes, determinar rotas, repetindo métodos desgastados de produção e gestão do cuidado.

As redes podem se fazer, como na experiência de grupos sujeitados, como redes frias, cujo efeito é o de homogeneização, de equivalência e de equalização da realidade. Mas também como redes quentes, como nos grupos sujeitos, atentos ao que estão fazendo, visando à construçáo de vínculos afetivos e de tecnologias relacionais, que incluem a gestáo coletiva dos processos de trabalho no dia a dia dos serviços (BARROS, 2014, p. 100).

Daí a necessidade de analisar os espaços coletivos e suas produçóes, pois a rede está em permanente fabricação, com distintos investimentos e remanejamentos entre 
grupalidades. Ora se produz como rede fria, ora se produz como rede quente. Ora como rede formal, ora como rede viva. E várias vezes como tudo isso ao mesmo tempo.

À medida que ia caminhando na pesquisa, o pensamento-corpo-sensibilidade afetava-se como um arco: distensóes, alargamentos e contraçôes. Fluxos heterogêneos produzindo conexôes, feixes de redes que não seguiam caminhos preestabelecidos nem alvos predeterminados; corpo multiplicidade armado de acordo com as afecçôes do encontro. Remanejamentos, deslocamentos, produção de territórios, distintas cartografias.

A escrita das narrativas foi potente como recurso de expressão viva dos afetos no corpo. As experimentaçôes, sensaçôes e pulsaçôes ultrapassam palavras que quase sempre as aprisionam. A imersão na pesquisa foi um intenso aprendizado, em ato, experimentando, processando, revendo, elaborando. As cartografias produzidas foram marcadas por afetos e sensibilidades do decorrer da experiência que em muitos momentos misturaram inquietaçóes, dúvidas e ativaram a aposta na potência das conexôes, dos encontros e suas produçôes. Vivências que também ampliaram e enriqueceram a pesquisadora-cartógrafa em mim por meio dos sustos, percalços, surpresas! Afirmação de que o conhecimento se faz pelo mergulho, pela imersão, pelos afetos, pelo pensamento-sensibilidade que opera por interesses, curiosidades, problematizaçôes vivas.

\section{Referências}

ABRAHÃO, A. L. et al. O pesquisador in-mundo e o processo de produção de outras formas de investigação em saúde. Revista Lugar Comum: estudos de mídia, cultura e democracia. Rio de Janeiro, n. 39, jan-abr 2013. Disponível em< http://uninomade.net/lugarcomum/39/>. Acesso em 15 jan. 2015.

BADUY, R. S. Gestão municipal e produção do cuidado: encontros e singularidades em permanente movimento. 2010. 183p. Tese (Doutorado em Ciências). Faculdade de Medicina, Universidade Federal do Rio de Janeiro, Rio de Janeiro, 2010.

BARROS, L. P.; KASTRUP, V. Cartografar é acompanhar processos. In: PASSOS, E.; KASTRUP, V.; ESCÓCIA, L. (Orgs.). Pistas do método da cartografia: pesquisa intervenção e produçâo de subjetividade. Porto Alegre: Sulina, 2009. p. 52-75.

BARROS, M. E. B. et. al. Verbos do apoio institucional em pesquisa: tranversalizar, transdisciplinarizar e fortalecer redes de trabalho-vida na saúde. In: PINHEIRO, R. et al. (Orgs.). Práticas de apoio e a integralidade no SUS: por uma estratégia de rede multicêntrica em pesquisa. Rio de Janeiro: CEPESC/ABRASCO, 2014. p. 83-110. 
BERTUSSI, D. C. O apoio matricial rizomático e a produção de coletivos na gestão municipal. 2010. 234p. Tese (Doutorado em Ciências). Faculdade de Medicina, Universidade Federal do Rio de Janeiro, Rio de Janeiro, 2010.

BRASIL. Ministério da Saúde. Secretaria de Gestão do Trabalho e da Educação na Saúde. Educação Permanente em Movimento. Material instrucional, 2014 (mimeo).

BRASIL. Ministério da Saúde. Conselho Nacional de Saúde. Resolução n. 466, de 12 de dezembro de 2012. Aprova diretrizes e normas regulamentadoras de pesquisas envolvendo seres humanos. Brasília, Diário Oficial da União, 12 dez. 2012 Disponível em: http://bvsms.saude. gov.br/bvs/saudelegis/cns/2013/res0466_12_12_2012.html. Acesso em: 12 mar. 2013.

CAMPOS, G. W. S. Um método para análise e co-gestão de coletivos: a constituição do sujeito, a produção de valor de uso e a democracia em instituiçóes: o método da roda. 3 ed. Sáo Paulo: Hucitec, 2007.

CAMPOS, G. W. S.; DOMITTI, A. C Apoio matricial e equipe de referência: uma metodologia para gestão do trabalho interdisciplinar em saúde. Cad. Saúde Pública, Rio de Janeiro, v. 23, n. 2, p. 399-407, fev. 2007.

COSTA, L. A.; ANGELI, A. A. C.; FONSECA, T. M. G. Cartografar. In: FONSECA, T. M. G.; NASCIMENTO, M. L.; MARASCHIN, C. (Orgs.) Pesquisar na diferença: um abecedário. Porto Alegre: Sulina, 2012. p. 45-48.

LAZZAROTTO, G. D.; CARVALHO, J. D. Afetar. In: FONSECA, T.M.G.; NASCIMENTO, M.L.; MARASCHIN, C. (Orgs.). Pesquisar na diferença: um abecedário. Porto Alegre: Sulina, 2012, p. 25-27.

PASCHE, D. F.; PASSOS, E. Inclusão como método de apoio para a produção de mudanças na saúde: aposta da Política de Humanização da Saúde. Saúde em Debate, Rio de Janeiro, v. 34, n. 86, p. 423-432, jul.-set. 2010.

PAULON, S. M.; PASCHE, D. F.; RIGHI, L. B. Função apoio: da mudança institucional à institucionalização da mudança. Interface, Botucatu, v. 18, supl. 1, p.809-820, 2014.

ROLNIK, S. Cartografia sentimental: transformaçóes contemporâneas do desejo. Porto Alegre: Sulina; Editora da UFRGS, 2006.

\section{Notas}

${ }^{1}$ Pesquisa realizada durante o doutorado no Programa de Pós-Graduação em Saúde Pública da Universidade de São Paulo e contou com o financiamento da Comissão de Aperfeiçoamento de Pessoal do Nível Superior (CAPES).

${ }^{2}$ Fala de um apoiador.

${ }^{3}$ Programa de Melhoria do Acesso e da Qualidade da Atenção Básica (PMAQ) é uma iniciativa do Ministério da Saúde que toma uma avaliaçáo externa quantitativa como móvel principal para produzir novos pactos e movimentos junto à gestão e as equipes da atenção básica nos municípios brasileiros. 


\section{Abstract}

Passages, scenes, cartographies: researching the production of the support device in the city of São Bernardo do Campo, Brazil

Cartography can be understood as a strategy that inspires the production of research interested in tracing, monitoring, investigating procedures and proposing analysis movements. This arrangement proved to be powerful to set the thinking in motion and to raise sensitivities that cut crossings and experiments during the doctoral research on the manufacture of health support in the city of São Bernardo do Campo, Brazil, where support was proposed as a network agent device. The offers of support varied according to the meetings and their arrangements, in the perspective that the production of care and management mobilizes connected and inseparable tactics. The article presents moments and clippings of this experience in cartography, through small narratives that illustrate concerns, chance and unpredictable immanent to this mobile geography and its multiplicity of possible. In the research, it was possible to follow many ways of interrogating and producing caregiving practices among the different actors, who put tension, disputes and the intense connection between management and daily care in circulation.

> Keywords: cartography; support; micropolitics of work; production of care. 